\title{
Glomus Tumour: A Retrospective Review of 15 Years Experience in A Single Institution
}

\author{
Rashdeen Fazwi, MS Ortho (UKM), Patricia Ann Chandran*, MPath (UM), \\ T Sara Ahmad**, FRCS (Glas) \\ Department of Orthopaedics, Hospital Tengku Ampuan Afzan, Pahang, Malaysia \\ *Department of Pathology, Universiti Malaya, Kuala Lumpur, Malaysia \\ ${ }^{* *}$ National Orthopaedic Centre of Excellence in Research and Learning (NOCERAL), \\ Universiti Malaya, Kuala Lumpur, Malaysia
}

\begin{abstract}
Glomus tumours (GT), neoplasms of the glomus body comprise $4.5 \%$ of upper limb tumours. Seventy-five per cent of these occur in the hand, and most are subungual (50\%). We performed a literature review and retrospective search of histopathologically confirmed GT seen from 1995 to 2009. Fifteen patients were identified, with an average age of 49.6 years. Eight were in the hand, 2 in the upper limb, 2 lower limb and 3 in the ear. Eighty-six per cent presented with pain and $50 \%$ underwent radiological investigation. Most diagnoses followed biopsy findings. Surgical excision resulted in a recurrence rate of $13 \%$. The average time to diagnosis was 3.3 years. The average duration of symptoms was 7 to 11 years with an average of 2 to 3 consultations prediagnosis. MRI remains the most useful imaging modality ( 82 to $90 \%$ sensitivity). Excision biopsy is the most common treatment. Greater awareness is needed for quicker diagnosis.
\end{abstract}

Key Words:

Glomus Tumour, Presentation, Imaging, Recurrence

\section{INTRODUCTION}

The glomus body is made up of glomus cells with smooth muscle properties and hence has the ability to contract, playing a part in thermoregulation by controlling blood flow to the skin. Glomus bodies are highly concentrated in the digits, palm and soles of the feet. Glomus tumour, a neoplasm of the glomus body, is generally a benign tumour, although malignant glomus tumour has also been described $^{14,15}$. Glomus tumour makes up 1-4.5\% of upper limb tumours $4,80 \%$ of which are found in the upper extremity, with the most common site being subungual $(50 \%)$. Glomus tumour has also been reported in almost every other human organ ${ }^{2,9,10,12,13,14}$

Patients typically present with a complaint of pain, which may remain undiagnosed for a long period of time. Grossly, glomus tumours may present as a soft mass with deep red purplish or bluish discoloration. The clinical triad of pinpoint tenderness, pain and hypersensitivity to cold was present in $63-100 \%$ of patients, resulting in clinical diagnosis in $90 \%$ of patients ${ }^{1}$. The average duration of symptoms was $7-11$ years with an average of 2-3 clinical consultations before the diagnosis was made.

Magnetic resonance imaging (MRI) remains the most useful imaging modality with $82-90 \%$ sensitivity in detecting the growth $^{6,78}$. Excision biopsy is the main treatment option with variable recurrence rate reported in the literature ${ }^{1,11,17}$. Fifty per cent of our cases required histopathological confirmation before arriving at a diagnosis.

\section{MATERIALS AND METHODS}

After performing a computer database search from pathology department records for patients with histopathological diagnosis of glomus tumour, we retrospectively reviewed the medical records of all patients treated at our institution between 1995 and 2009. Eighteen records with a histological diagnosis of glomus tumour were found and the records were traced. Three patient folders were untraceable.

The records were reviewed for c data including: age, sex and race, location of lesion, presentation time with respect to the initial complaints, first clinical consultation and time of diagnosis, presenting symptoms and clinical signs, radiological imaging modalities employed, pathology and staining, follow-up, outcome of treatment and complications.

\section{RESULTS}

Patient data is presented in Table I. There were 6 men and 9 women in the study population. The mean age was 49.6 years (range, 17-74 years). With respect to the Malaysian multiracial population, the racial distribution was: 5 Malays, 5 Chinese; 4 Indians and one other. Anatomical sites of the 


\begin{tabular}{|c|c|c|c|c|c|c|c|c|c|c|c|c|c|c|c|}
\hline 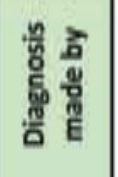 & $\begin{array}{l}\frac{5}{8} \\
\frac{g}{2} \\
\frac{a}{a} \\
\frac{a}{x}\end{array}$ & 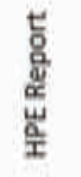 & 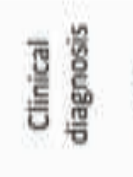 & 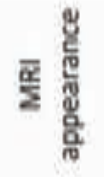 & 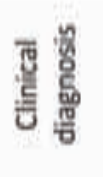 & 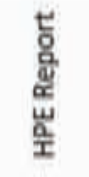 & 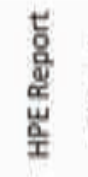 & 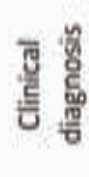 & 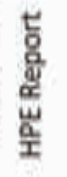 & 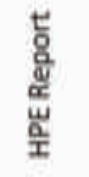 & 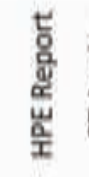 & 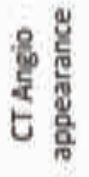 & 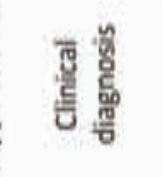 & 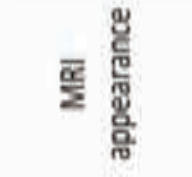 & 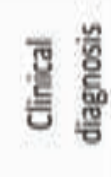 \\
\hline 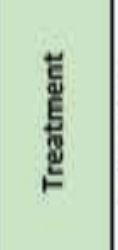 & 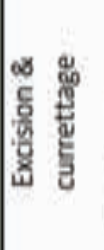 & 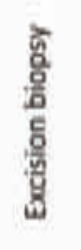 & 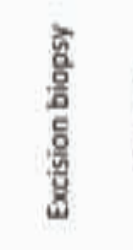 & 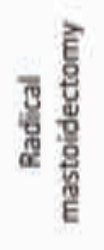 & 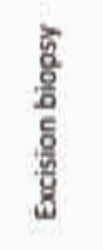 & 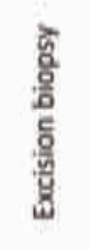 & 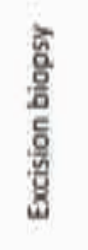 & 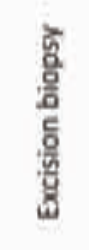 & 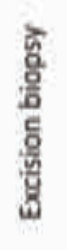 & 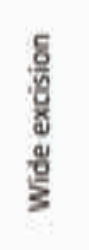 & 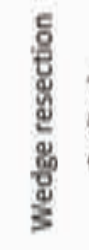 & 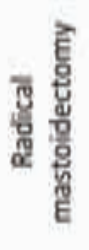 & 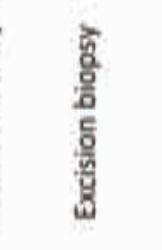 & 总 & 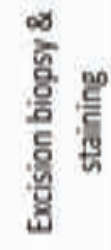 \\
\hline $\begin{array}{l}\text { 해 } \\
\text { 윰 } \\
\text { 맹 }\end{array}$ & 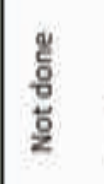 & 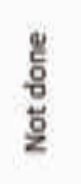 & 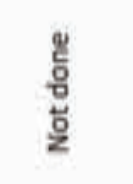 & $\begin{array}{l}\frac{\ddot{\nu}}{8} \\
\frac{0}{\frac{\pi}{2}}\end{array}$ & 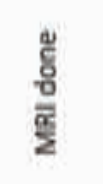 & 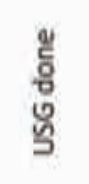 & 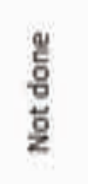 & 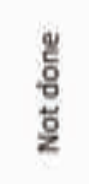 & 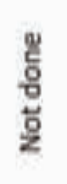 & 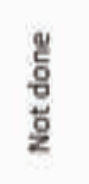 & $\begin{array}{l}\text { gू } \\
\text { 을 } \\
\text { 물 }\end{array}$ & $\begin{array}{l}\text { Lू } \\
\text { है }\end{array}$ & 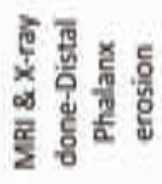 & $\frac{\Xi}{\frac{\alpha}{\Sigma}}$ & 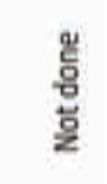 \\
\hline 营 & 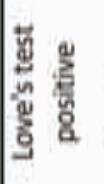 & $\begin{array}{l}5 \\
\frac{9}{5} \\
0 \\
2\end{array}$ & 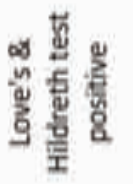 & 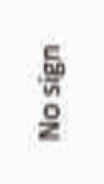 & 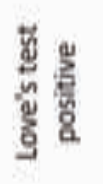 & $\begin{array}{l}5 \\
\text { जू } \\
\text { 울 }\end{array}$ & $\begin{array}{l}\text { 嵒 } \\
\text { 을 }\end{array}$ & 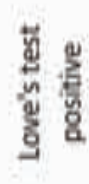 & $\begin{array}{l}5 \\
\frac{5}{2} \\
\frac{0}{2}\end{array}$ & 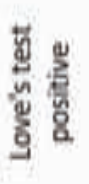 & $\begin{array}{l}\text { 总 } \\
\text { है } \\
2\end{array}$ & $\begin{array}{l}5 \\
\frac{5}{n} \\
\frac{0}{2}\end{array}$ & 泀营 & $\begin{array}{l}\text { 点 } \\
\text { 足 }\end{array}$ & 苞产 \\
\hline 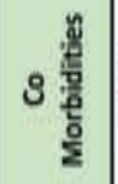 & 这 & 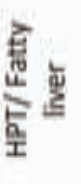 & 올 & $\frac{9}{2}$ & 을 & 울 & $\frac{0}{z}$ & 吉 & 울 & 울 & $\frac{0}{z}$ & 울 & 올 & 운 & 을 \\
\hline $\begin{array}{l}\text { है } \\
\text { हूँ } \\
\text { है }\end{array}$ & 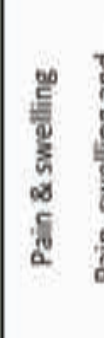 & 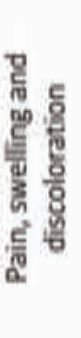 & 而 & 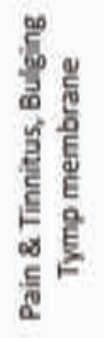 & 댕 & 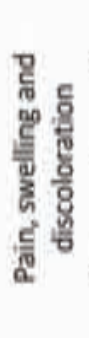 & 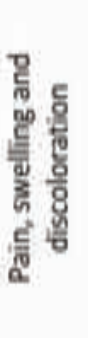 & 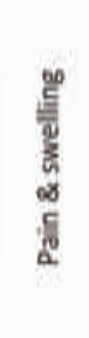 & 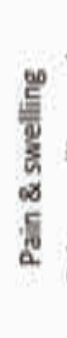 & 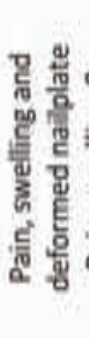 & 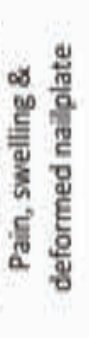 & 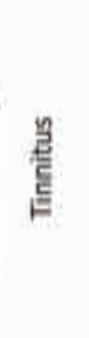 & $\begin{array}{l}\text { है } \\
\text { है } \\
\text { है } \\
\infty \\
5 \\
\text { हू. }\end{array}$ & 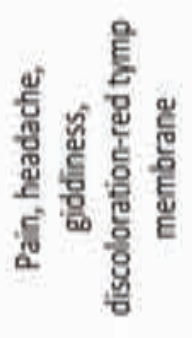 & 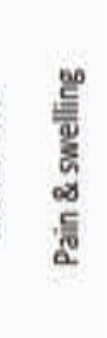 \\
\hline 䎡要 & 6 & 0 & 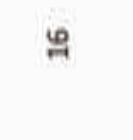 & 0 & $\cong$ & M & $\ddot{\nexists}$ & $\hat{\sim}$ & 8 & $\pi$ & ఏ & $\vec{N}$ & 88 & $m$ & $\kappa$ \\
\hline $\begin{array}{l}\text { हू } \\
\text { है } \\
\text { g. }\end{array}$ & 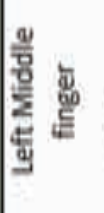 & 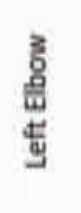 & 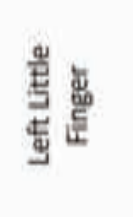 & $\begin{array}{l}\text { 营 } \\
\text { 离 } \\
\text { 总 }\end{array}$ & 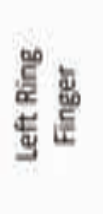 & E & 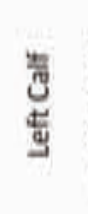 & 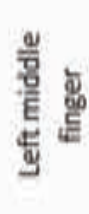 & 卷 & 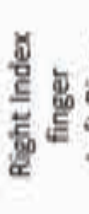 & 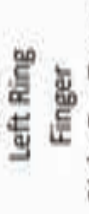 & 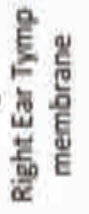 & 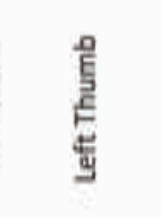 & 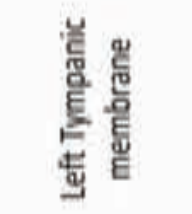 & 总 \\
\hline 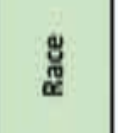 & $\frac{8}{5}$ & $\frac{\frac{5}{2}}{2}$ & $\frac{\frac{\pi}{20}}{2}$ & 遏 & 惡 & $\frac{\frac{\pi}{20}}{\frac{\pi n}{2}}$ & $\frac{\frac{6}{\pi}}{2}$ & $\begin{array}{l}\text { 대 } \\
\text { 몰 }\end{array}$ & 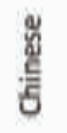 & 돔 & 造 & $\frac{\text { है }}{5}$ & $\frac{\frac{7}{20}}{2}$ & $\begin{array}{l}\text { 대 } \\
\text { 奠 }\end{array}$ & $\begin{array}{l}\text { 돔 } \\
\text { 吾 }\end{array}$ \\
\hline ฉ & 4 & $\Sigma$ & 4 & $\Sigma$ & 4 & $\Sigma$ & $=$ & $\Sigma$ & $\Sigma$ & 4 & 4 & 4 & 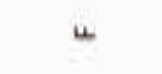 & 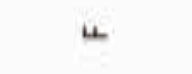 & \\
\hline \& & $\mathcal{F}$ & 6 & ถี & ल् & $\vec{F}$ & $\ddot{A}$ & $\stackrel{\infty}{\sim}$ & \& & \& & in & 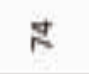 & ภू & $\ddot{m}$ & $g$ & n \\
\hline$\stackrel{\circ}{z}$ & $\Rightarrow$ & $N$ & m & * & in & 6 & n & $\infty$ & a & ㅇ & $\Rightarrow$ & $\simeq$ & $m$ & $\nexists$ & $\cong$ \\
\hline
\end{tabular}


tumours were as follows: hand, 8; elbow, 2; leg, 2; and middle ear cavity, 3 . The average time delay before the patient consulted a physician after the appearance of the first symptoms was 3.2 years. The average time taken to come to a diagnosis after the first physician visit was 1.3 years and the average time taken to reach a diagnosis after the onset of symptoms was 3.3 years.

Thirteen patients $(86 \%)$ presented with pain associated with localized tenderness and 9 patients $(60 \%)$ had a clinically noticeable swelling at the site of pain. Only 4 patients (26\%) presented with an associated discoloration and 2 EBT patients (13\%) presented with tinnitus. Only 2 of the 8 digital glomus tumour patients presented with deformity of the nail plates. The most common clinical sign was the Love's test (pin point tenderness), which was present in $7(50 \%)$ of the patients. One patient complained of cold intolerance. The Hildreth, cold and transillumination tests were not employed on any patients.

Eight patients underwent imaging procedures: MRI, 4; plain radiograph, 1; CT angiography, 2; and ultrasonography, 1. Imaging results helped the pathologist to make the diagnosis of glomus tumour in 2 of the patients (one CT angiogram and one MRI). Otherwise, diagnosis was made on the basis of: clinical presentation, 5; histopathological confirmation, 8; and radiological appearance, 2 . Clinical diagnosis was made much earlier if the patient was seen by a hand surgeon. Initial differential diagnosis offered to patients included neuroma, osteoarthritis, Reynaud's phenomenon, pyogenic granuloma, haemangioma and chronic paronychia.

Thirteen patients underwent excision biopsy while the ENT cases underwent radical mastoidectomy and meatoplasty. The mean duration of follow up was 18.6 months except follow up of the ENT cases exceeded 8 years. Two patients from the digital group (13\%) had clinical recurrence for which repeat excision was performed.

Our pathologists readily recognized the typical characteristics of glomus tumour. Only one specimen required histochemical staining resulting in positive actin and negative S100 stains to confirm the diagnosis.

\section{DISCUSSION}

Glomus tumours are rare vascular tumours, which arise from glomus bodies richly situated in the reticular dermis. These neuromyoarterial structures play a role in thermoregulation by regulating skin circulation ${ }^{1,2,3}$. These benign mesenchymal tumours are commonly found in the subungual region of digits, and often present as tender purple coloured subcutaneous nodules. Pain is often aggravated by temperature changes ${ }^{4}$. The growths are usually small (less than one $\mathrm{cm}$ ) and average about $3-4 \mathrm{~mm}$ in diameter ${ }^{5}$. Glomus tumours represent about $1.5 \%$ of all soft tissue tumours.
Glomus tumour has been described in almost all other organs in the human body. In our study population, extra-digital distribution was $47 \%$. Five out of 7 (71\%) extra-digital glomus tumour occurred in men in contrast to $12 \%$ of digital glomus tumour that occurred in men. The tumour occurred all age groups, had a female to male ratio of 1.3:1 and was equally distributed among the 3 major races in Malaysia.

The average time to diagnosis in our series was 3.3 years with the longest being 10 years. The clinical diagnosis was obtained much earlier in patients seen by the resident hand surgeon and those seen at our institution later in the study period. This reflects the importance of clinical experience and awareness regarding the diagnosis of the condition. Differential diagnosis considered prior to actual diagnosis included neuroma, osteoarthritis, Reynaud's phenomenon, pyogenic granuloma, haemangioma and chronic paronychia.

Several clinical tests have been described to aid in the diagnosis, including the Love's Test ${ }^{7}$, Hildreth's test ${ }^{8}$, transillumination and the cold test. Love's test pinpoints localization of tenderness, and has a reported sensitivity and specificity of $100 \%$ and $0 \%$, respectively. Hildreth's test, a modulation of pain and tenderness, accomplished by inflating tourniquet thus inducing ischemia, has a reported sensitivity and specificity range of $77.4-92 \%$ and $91 \%$ $100 \%$. Transillumination of the digit and observation of an opaque reddish mass with illumination has a reported sensitivity and specificity of $23-38 \%$ and $90 \%$, respectively. The cold test, provocation of pain with the application of cold water or ethyl alcohol, has a reported sensitivity and specificity of $100 \%$ for both ${ }^{8,9}$.

Various radiological imaging modalities have been used to aid in the diagnosis of glomus tumour. Half of our patients (8/15) underwent imaging procedures which included MRI, CT Angiogram, ultrasonography and plain radiographs. These investigations were helpful in coming to a diagnosis in only 2 of the study patients. On MRI, primary glomus tumours typically appear as a dark, well-defined mass on T1 weighted images, a high signal intensity on T2 weighted images and a bright enhancing mass on T1 post-gadolinium fat saturation images ${ }^{9,10}$. The specificity of MRI for glomus tumours is estimated at $50 \%$. This modality provides excellent contrast between the neoplasm and normal tissue, but it cannot differentiate between glomus tumour and solid neoplasm using the T2-weighted image. On T1-weighted images, a low signal accompanied by a high signal dot indicates a nidus within a hypervascular mass, such as a glomus tumour ${ }^{11,12}$.

Contrast-enhanced CT, used for extra-digital tumours, shows peripheral nodular or homogenous strong enhancement in the arterial phase and prolonged enhancement in the delayed phase ${ }^{13}$. Plain radiographs may show larger tumours, however, with smaller sized tumours may appear as normal ${ }^{1}$. Cortical thinning or bony cortical erosions can be seen with 
long standing lesions and has been present in up to $60 \%$ of radiographs in some series ${ }^{10,14}$.

Ultrasonography with high-frequency transducers has been found to be most useful when the tumour is less than $2 \mathrm{~mm}$ in size and located in the lateral subungual area. Even when the tumour is not palpable, the positive prediction rate with colour Duplex sonography is $100 \%{ }^{11}$.

Glomus tumours may be classified as solitary or multiple. Commonly located in the fingertips, solitary tumours are often encapsulated. The more rare multiple glomus tumours have earlier onset, and are inherited in an autosomal dominant manner with incomplete penetrance ${ }^{3,15}$. Based on its 3 typical components, i.e., glomus cells, vasculature, and smooth muscle cells, glomus tumours may be classified as solid glomus tumour (with poor vasculature and a scant smooth muscle component), glomangioma (with a prominent vascular component), or glomangiomyoma (with prominent vascular and smooth muscle components) ${ }^{5}$.

Histopathologically, glomus cells present with round to oval nuclei and striking eosinophilic cytoplasm after haematoxylin adenosine staining. Immunohistochemically, these tumours stain positively for vimentin, neuron-specific enolase and muscle actin, but negatively for cytokeratin and S100 ${ }^{16}$. Malignant glomus tumours are rare. These glomangiosarcomas are often located in the lower extremity or deep viscera, with approximately 8 cases reported in the hand ${ }^{17}$. These tumour cells are strongly and diffusely positive for vimentin, smooth muscle actin and muscle-specific actin, and focally positive for the antiapoptotic marker bcl-2. Metastasis is rare, and wide excision is curative with a low recurrence rate ${ }^{18}$.

Recommended treatment for glomus tumours is complete surgical excision ${ }^{19}$. In our series, the recurrence rate was $13 \%$. True recurrence appears within weeks of surgery and usually represents inadequate excision ${ }^{20}$. Those that reappear years later are believed to be a result of the development of a new tumour near the site of the excision ${ }^{21}$.

Multiple surgical approaches have been described in the literature, namely the transungual, lateral subperiosteal and the Keyser-Littler approach ${ }^{14,20,22}$. With the transungual approach, the nail plate is removed and an incision is made on the nail bed, the nail bed is elevated adequately exposing the tumor for removal and is followed by meticulous repair. In the lateral subperiosteal approach, an incision is made dorsal to the mid-lateral line. Dissection is carried down to the distal phalanx and a dorsal flap consisting of skin, nail plate, nail bed and germinal matrix tissue is elevated in a single layer ${ }^{14}$. The Keyser-Littler approach is also a lateral approach made through a high mid-lateral approach below the paronychial fold. The distal phalangeal ligament, which provides lateral support to the nail matrix and nail plate, is identified and retracted. The nail matrix is then elevated over the ligament and the dorsal cortex of the distal phalanx ${ }^{22}$. The transungual approach affords better exposure ${ }^{20}$. Nail deformities are better avoided with the lateral subperiosteal approach. We have no experience with the lateral subperiosteal approach. None of our patients had nail deformities following use of the transungual approach for removal of the tumour.

\section{CONCLUSION}

In this retrospective chart review, Glomus tumours occurred in several organs but most were subungual (more than 50\%). Average time to diagnosis was 3.3 years. To achieve earlier diagnosis, general practitioners and general orthopaedic surgeons need to be more aware of small lesions with pinpoint tenderness, as $86 \%$ of patients in the present study presented with pain. MRI was the most useful imaging modality and excision had a $13 \%$ recurrence rate. 


\section{REFERENCES}

1. Carroll RE, Berman AT. Glomus tumors of the hand: review of the literature and report on twenty-eight cases. J Bone Joint Surg [Am] 1972; 54(4): 691-703.

2. Schiefer TK, Parker WL, Anakwenze OA, Amadio PC, Inwards CY, Spinner RJ. Extradigital glomus tumors: a 20-year experience. Mayo Clin Proc. 2006; 81(10): 1337-44.

3. Bhaskaranand K, Navadgi BC. Glomus tumour of the hand. J Hand Surg [Br] 2002; 27(3): 229-31.

4. Weiss SW, Goldblum JR. Enzinger and Weiss's. Soft Tissue Tumors. 4th ed. Philadelphia: PA: Mosby Inc; 2001.

5. Gombos Z, Zhang PJ. Glomus tumor. Arch Pathol Lab Med. 2008; 132(9): 1448-52.

6. Nebreda CL, Urban BJ, Taylor AE. Upper extremity pain of 10 years duration caused by a glomus tumor. Reg Anesth Pain Med. 2000; 25(1): 69-71.

7. Love JG. Glomus tumors: diagnosis and treatment. Proc Staff Meet, Mayo Clin. 1944; 19: 113-6.

8. Giele H. Hildreth's test is a reliable clinical sign for the diagnosis of glomus tumours. J Hand Surg [Br] 2002; 27(2): 157-8.

9. Matloub HS, Muoneke VN, Prevel CD, Sanger JR, Yousif NJ. Glomus tumor imaging: use of MRI for localization of occult lesions. J Hand Surg [Am] 1992; 17(3): 472-5.

10. Sorene ED, Goodwin DR. Magnetic resonance imaging of a tiny glomus tumour of the fingertip: a case report. Scand J Plast Reconstr Surg Hand Surg. 2001; 35(4): 429-31.

11. Chen SH, Chen YL, Cheng MH, Yeow KM, Chen HC, Wei FC. The use of ultrasonography in preoperative localization of digital glomus tumors. Plast Reconstr Surg. 2003; 112(1): 115-9.

12. Kamano M, Kazuki K. Glomangioma arising from the superficial palmar arch in the hand: case report. Clin Orthop Relat Res. 2004; (419): 162-4.

13. Kim JK, Won JH, Cho YK, Kim MW, Joo HJ, Suh JH. Glomus tumor of the stomach: CT findings. Abdom Imaging. 2001; 26(3): 303-5.

14. Vasisht B, Watson HK, Joseph E, Lionelli GT. Digital glomus tumors: a 29-year experience with a lateral subperiosteal approach. Plast Reconstr Surg. 2004; 114(6): 1486-9.

15. Ghaly RF, Ring AM. Supraclavicular glomus tumor, 20 year history of undiagnosed shoulder pain: a case report. Pain. 1999; 83(2): 379-82.

16. Lee IJ, Yoo YM, Lim H, Park MC. Glomus tumor of the back: a rare location. J Craniofac Surg. 2009; 20(6): 2153-5.

17. Folpe AL, Fanburg-Smith JC, Miettinen M, Weiss SW. Atypical and malignant glomus tumors: analysis of 52 cases, with a proposal for the reclassification of glomus tumors. Am J Surg Pathol. 2001; 25(1): 1-12.

18. Oh SD, Stephenson D, Schnall S, Fassola I, Dinh P. Malignant glomus tumor of the hand. Appl Immunohistochem Mol Morphol. 2009; 17(3): 264-9.

19. Keles B, Linthicum FH. Glomus tumors. Otol Neurotol. 2009; 30(4): 577-8.

20. Van Geertruyden J LP, Goldschmidt D, et al. Glomus tumours of the hand. J Hand Surg [Br] 1996; 21: 257-60.

21. Rettig AC, Strickland JW. Glomus tumor of the digits. J Hand Surg [Am] 1977; 2(4): 261-5.

22. Keyser JJ. The nails. In: Converse JM, McCarthy JG, eds. Reconstructive plastic surgery, 2nd ed. Vol. VI: The hand and upper extremity. Philadelphia: W.B. Saunders; 1977. 